\title{
Communication across cultures
}

As the end of the academic year approaches many teachers in schools of architecture find themselves once again immersed in the assessment of student design work, and in counselling individual students who for one reason or another find themselves unable to understand how their grade tallies with their understanding of the verbal feedback they have received. Both pursuits involve us in negotiating an interface between a culture of architectural understanding and judgement, that is to some degree tacit, and institutional structures that require us to codify and quantify our judgements. Competence in the use of the language in which these shared understandings and judgements are forged is not the least of the skills we require of our students. And like any language fluency is hard won. Picture then an educational milieu where the institutional structures of pedagogical assessment with which we are so familiar - the learning outcomes, the criteria of assessment - are nowhere to be found; a world such as that evoked by Igor Marjanović in his portrayal of the Architectural Association School of Architecture under the chairmanship of Alvin Boyarsky (pp. 165-174). During this era the pedagogical structure at the AA was for a time free of both curriculum and examinations, as Boyarsky said: 'Instead, a rich table [was] laid'.

The difficulty of communicating across cultures is thoughtfully summarised by Keith Diaz Moore and Lyn Geboy (pp. 105-114) in their critique of what constitutes 'evidence' in Evidence Based Design, which, they explain, is the offspring of Evidence Based Medicine. In medicine the pinnacle of evidential excellence is occupied by double blind trials, but evidential standards should, they argue, relate to values and epistemological assumptions relevant to the practitioners who are the putative beneficiaries of the insights gained through the gathering of such 'evidence'. So the transference of a medical criterion of excellence directly into the field of 'environmental' assessment (the judgement of architectural environments), where fundamentally different styles of thought prevail in the field of practice, results in reductionism and redundancy - absurdity even. What are required instead are criteria defined in a manner relevant to the practice under scrutiny. In architectural design, Moore and Geboy argue, 'intuitivist' and 'interpretivist' styles of thinking prevail; in medicine the hegemonic 'traditional scientific', hence the mismatch.

To provide a full specturm of epistemological styles Moore and Geboy add 'technical-rationality' and 'pragmatism'. The styles of thought are presented not so much as silos of impenetrable difference as strong tendencies in one direction or another. Nonetheless it is perhaps possible to characterise the contributions to this issue of arq as falling within one category or another. Whilst Kali Tzortzi's Space Syntax comparison of two museums (pp. 129-138) rests on the epistemological base of 'traditional science', Rosa Schiano-Phan's presentation of porous ceramic blocks used in passive cooling (pp. 139-151) can be characterised as 'technical-rational'. Nicole Sully's meditation on memorials to Diana, Princess of Wales (pp. 115-128) sits firmly within an 'interpretative' style, whilst Simon McCormack's appreciation of a Milanese apartment building by Giuseppe Terragni (pp. 92-103) is surely 'pragmatic' - a style where 'the significance of an idea is gauged on the basis of its practical utility'. Joseph Bedford, in describing an exchange of ideas and influences between James Stirling and Colin Rowe (pp. 153-164) addresses the heritage of 'rational' poetics in International Modernism which sought to reconcile 'artistic' and 'scientific'. Stirling's critical writing could be taken as exemplary of the 'intuitivist/ interpretavist' thinking which for Moore and Geboy is typical of architectural practitioners, but in the final analysis Bedford's incisive presentation serves to remind us of both the slipperiness of categories and the potential for artistic expression to surpass any secondary description.

THE EDITORS 


\section{architectural research quarterly}

\section{Subscribe now for 2010}

Innovative in conception, unique in breadth and generously illustrated, this pace-setting quarterly publication from Cambridge University Press links, on a global scale, the worlds of architectural practice and research. arq regularly includes extensive peer-reviewed sections on design, history, theory, construction, environmental design, information technology and practice - as well as structures, urbanism and documents. These are supplemented by letters, reports, reviews, a directory of specialist research centers and consultancies and an annual index. Each issue opens with a leader and closes with insight, a personal end-piece. In its ten year history, arq has published work from all over the world: from Chile to Sweden and from Japan to the Netherlands - with a strong representation from the United Kingdom and United States. arq, like architecture itself, is all-embracing and written by and for both practitioners and academics. It provides an outlet for all those who wish to disseminate their work to an international audience.
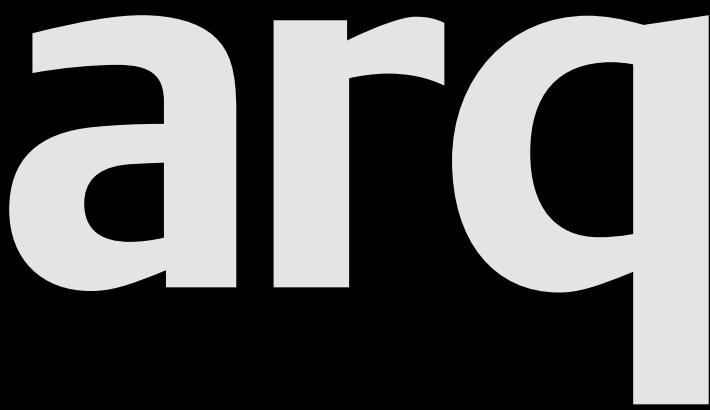

Please enter my subscription to

arq: architectural research quarterly, volume 14, 2010

$E_{193} / \$ 320$ institutions print and electronic
$E_{31} / \$ 52$ students print only
$E_{43} / \$ 66$ individuals print only

EU residents only. VAT may be payable at your local rate if not registered.

Our VAT registration number: GB 214141614 If registered, your VAT registration no:

Total subscription payment $£ / \$$ Eu residents only, if not registered add VAT at appropriate rate

Canadian residents, add 7\% GST \$

Total $\mathbf{E} / \mathbf{S}$

Name

Address

\section{Payment enclosed}

Cheque in sterling or US dollars

(payable to Cambridge University Press)

| Credit Card - VISA | MasterCard | American Express (delete where applicable)

Card no

Expiry date

Signature

Photocopy this page and send your order to: Journals Customer Services, Cambridge University Press, The Edinburgh Building, Cambridge, CB2 8RU, UK

$T+44(0) 1223326070$

F +44 (o) 1223315052

E journals@cambridge.org

or in USA, Canada and Mexico send to:

Cambridge University Press, 32 Avenue of the

Americas, New York NY 10013-2473, USA

T (914) 9379600

F (914) 9374712

E journals_subscriptions@cup.org 